\title{
Article
}

\section{Variations in Plant Growth Characteristics due to Oxygen Plasma Irradiation on Leaf and Seed}

\author{
Nobuya Hayashi ${ }^{1, *}$, Kyotaro Yamamoto ${ }^{1}$ \\ ${ }^{1}$ Interdisciplinary Graduate School of Engineering Sciences, Kyushu University, Fukuoka 816-8580, Japan \\ *Correspondence: hayashi.nobuya.056@m.kyushu-u.ac.jp
}

\begin{abstract}
Gene expression variations of plant leaf are investigated by irradiating seed and leaf with oxygen or air plasmas. Enhancement of leaf growth is induced by oxygen plasma irradiation on seeds, which is supported by increased gene expression for protein synthesis, oxidative-reduction reactions and decreased gene expression concerning DNA methylation and histone modification. Suppression of leaf growth is observed by the oxygen plasma, which would be owing to increased gene expression concerning heat shock protein and redox reaction, and decreased expression of photosynthesis and glycoprotein. Also, gene expression variation due to air plasma irradiation is almost same as that of oxygen plasma. Active oxygen species are major factors in both oxygen and air plasmas for the variation of gene expressions in plant.
\end{abstract}

Keywords: keyword 1; oxygen plasma 2; active oxygen species 3; plasma irradiation on seed and leaf 4; growth enhancement 5; gene expression

\section{Introduction}

Recently, useful effects of plants such as enhancements of germination, growth and antioxidative activity have been investigated, which are induced by active particles in plasmas [1-11]. Enhancements of root and stem lengths and leaf area have been observed [1-6]. Restriction effect of plant growth have also been observed under some plasma conditions [6]. To utilize these effects on plants and to increase producibility of agricultural products, detailed clarification of response mechanism of plants against the plasma irradiation is necessary. These growth enhancement effects would be owing to ions and active particles generated in plasmas. However, mechanism and response process of biological functions by the enhancement have not been clarified yet. Gene expression analysis of Arabidopsis seed irradiated with plasmas has been performed to elucidate the growth enhancement mechanism [7-9]. Observed gene expressions indicate that genes of the plant growth, stress response, hormone response, photosynthesis are upregulated. From these results, increase of the energy production pathways would occur after the germination. 


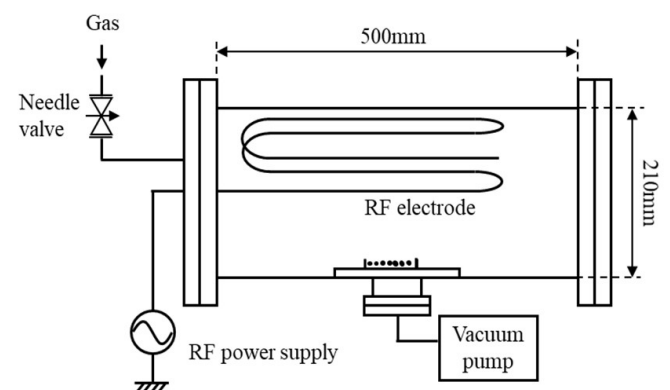

Figure 1 Schematic diagram of low-pressure plasma generation device.

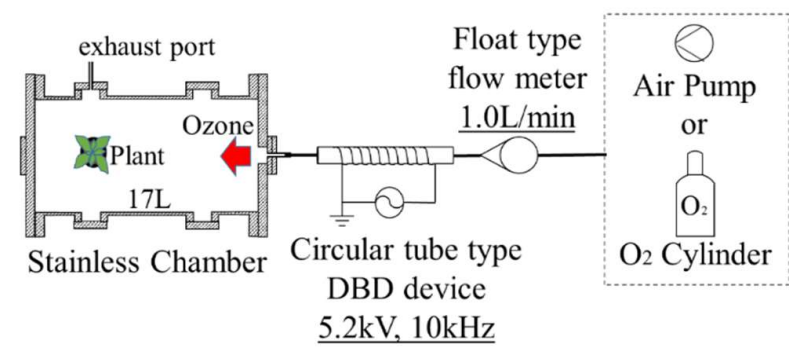

Figure 2 Schematic diagram of atmospheric plasma treatment device.

As research on the enhancement of plant growth by plasma irradiation, plasma irradiation of seeds and gene expression analysis of seeds have been mainly conducted. On the other hand, plasma irradiation to plants after germination and gene expression analysis for functional changes induced by plasma irradiation have not been performed. Gene expression in seeds is involved in germination and cell differentiation of seeds, and information on growth of sprout can be obtained [10]. To investigate the growth process of leaf, gene expression of leaf must be analyzed. In this study, to investigate the gene expression variation in leaf by irradiation seeds or leaves, both seed and leaf are irradiated with oxygen plasma, and then responses of plant leaves after germination to the oxygen plasma irradiation are determined. Effects of plasma irradiation on plant growth process are investigated by (i) gene expression of leaf that grows from seeds irradiated with plasma, (ii) gene expression of leaf that is irradiated with plasma.

\section{Experimental apparatus and methods}

Figure 1 shows a schematic diagram of a low-pressure capacitively coupled plasma apparatus [12-16]. The vacuum chamber is a stainless-steel cylindrical container with an inner diameter of $210 \mathrm{~mm}$, a length of $480 \mathrm{~mm}$, and a volume of $17 \mathrm{~L}$. A high-frequency electrode is installed in the upper part of the chamber, and a sample holder on which the object to be processed is placed is installed in the diffused region. The distance between the electrode and the inner wall of the chamber is $3 \mathrm{~cm}$, and the distance between the electrode and the sample holder is $17 \mathrm{~cm}$. A high-frequency power supply with a frequency of $13.56 \mathrm{MHz}$ and a load matching device were used for the plasma production. Plasma is produced in the gap between the high-frequency electrode and inner wall of the grounded chamber. Material gas for plasma production is pure oxygen and introduced into the chamber through the fine valve. Species and production amount of active oxygens in the plasma are measured using the light emission spectroscopy. Time variation of the temperature in the chamber is measured, because increase of the temperature in the chamber would affect gene expression of seeds. The temperature has hardly increased with plasma irradiation for 3min. After the irradiation for $30 \mathrm{~min}$, After the irradiation for 30 min, the temperature around seeds increases about $10^{\circ} \mathrm{C}$.

The torch-type dielectric barrier discharge (DBD) device is used for the plasma irradiation to leaf under atmospheric pressure [17-20]. Figure 2 illustrates the schematic diagram of plasma treatment device using the atmospheric plasma torch. A ceramics tube with dimension of $6 \mathrm{~mm}$ in outer diameter, $4 \mathrm{~mm}$ in inner diameter and $100 \mathrm{~mm}$ in length is used as a torch tube employing as the dielectric for discharge, and the copper film wounds on the outer surface of the ceramics tube as the grounded electrode. Cylindricalshaped stainless-steel mesh as the cathode is set inside the ceramics tube touching on the inner wall of the tube. When the high frequency electrical power of $10 \mathrm{kHz}$ is applied on the mesh electrode, the DBD occurs in the tube. Discharge voltage and current are measured using the high voltage probe and the Rogowski coil with a oscilloscope, respectively. 
The voltage and frequency applied on the cathode are set at $5.2 \mathrm{kV}$ and $10 \mathrm{kHz}$, respectively. Oxygen gas or air flows into the torch tube with the flow rate of $1.0 \mathrm{~L} / \mathrm{min}$. DBD in the oxygen gas or the air at atmospheric pressure generates a plasma including ozone,

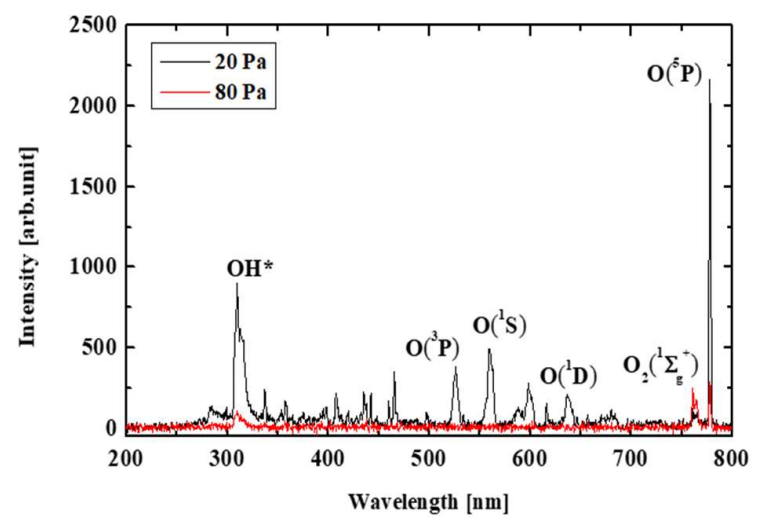

Figure 3 Typical light emission spectra of low-pressure oxygen plasma.

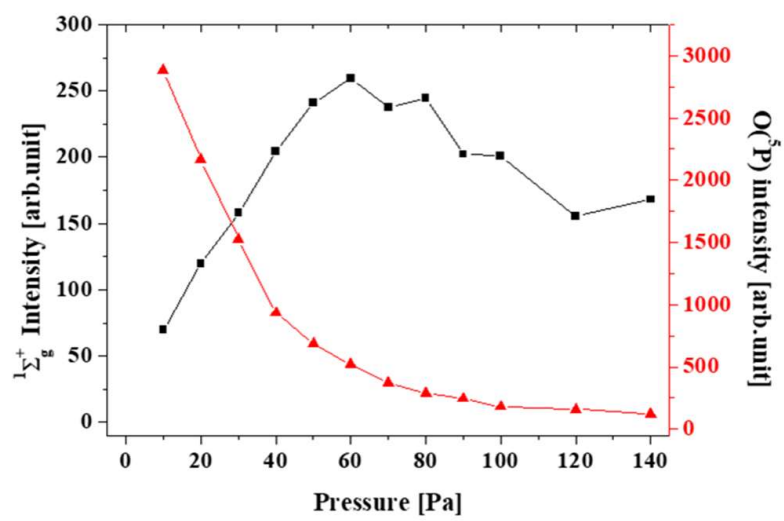

Figure 4 Light emission intensities from active oxygen species in low-pressure oxygen plasma.

and also nitrogen oxides are produced in the air plasma.

Ozone has sufficiently long lifetime to reach plants from the discharge region. In this experiment, the ozone CT value is used as the indicator of oxygen plasma effect on plants. The product of the ozone concentration $\mathrm{C}$ and the contact time $\mathrm{T}$ with ozone is defined as the ozone CT value [ppm•min] [21,22]. The concentration of ozone inside the chamber is measured by a gas detection tube using indigo dye. The ozone CT value was calculated in consideration of the fact that the ozone concentration in the chamber changes gradually with time until it is saturated, and in each case, the plasma irradiation parameters for the plants were determined so that the ozone CT value was constant. The production amount of active oxygen that is almost proportional to the CT value is measured using a chemical indicator (CI) in both cases of the low pressure and atmospheric pressure plasmas [23,24]. When active oxygen species irradiate the CI that is phthalocyanine dye pasted on a thin strip, the color of the CI changes due to oxidation of phthalocyanine. The total amount of active oxygen is quantified by the color variation using a spectrometer.

As sample plant, Arabidopsis thaliana wild type, Columbia-0 is supplied from the Institute of Physical and Chemical Research, RIKEN. Arabidopsis thaliana has been grown according to the table the guideline of plant growth of RIKEN bio resource research center. For the growth of plants, an artificial climate chamber is used to grow plants those are irradiated with the fluorescent light of 3000 Lux. Arabidopsis thaliana cultivated for one month after sowing seeds was placed in the stainless-steel container together with the pot and soil. After that, plasma produced by dielectric barrier discharge was introduced into the chamber. In the case of the oxygen plasma, the plant was irradiated with the plasma for $10 \mathrm{sec}$ and 3 times with the interval of $24 \mathrm{~h}$ to avoid serious ozone damage on the plant. Also, plasma irradiates seeds for $20 \mathrm{sec}$ in the case of the air plasma. In both cases, the CT value of ozone is adjusted same, $1 \mathrm{ppm} \cdot \mathrm{min}$.

The leaf area was used as index for the growth of the plant. The area was measured from the captured images of leaves using the image processing software (Image J). The total area of 5 leaves were measured in descending order of area and evaluated using the average value. To clarify the biological reactions such as growth enhancement and antioxidation ability those are induced by plasma irradiation, variation of gene expression of plants after the plasma irradiation are investigated. Gene function annotation bioinformatics microarray analysis was performed as one of the gene expression analysis methods. Gene expression can be comprehensively analyzed by extracting RNA from Arabidopsis seeds and leaves and preparing a microarray (Arabidopsis oligo DNA microarray Ver.4.0, Agilent) in which all probes corresponding to each gene are arranged. 
Annotations of genes those are expressed due to the plasma irradiation are obtained from expressed genes with p-value less than 0.05 using the database for annotation, visualization and integrated discovery $[25,26]$. The protein produced can be identified from the obtained gene expression profile, and the biological reaction caused by plasma irradiation can be estimated.

\section{Experimental results and discussion}

\subsection{Production of active oxygen species}

Figure 3 shows typical light emission spectra in the diffused region of low-pressure oxygen plasma with the pressure of 20 and $80 \mathrm{~Pa}$. Significant peaks are observed at 309,762 and $777 \mathrm{~nm}$ in both pressure case, even though the intensity at the pressure of $80 \mathrm{~Pa}$ is lower than that of $20 \mathrm{~Pa}$. These peaks correspond to $\mathrm{OH}$ radical, singlet oxygen molecule $\mathrm{O}_{2}\left({ }^{1} \sum_{\mathrm{g}^{+}} \rightarrow{ }^{3} \sum_{\mathrm{g}^{-}}\right)$and atomic oxygen $\mathrm{O}\left({ }^{5} \mathrm{P}\right)[12,14,27,28]$, respectively. Also, peaks at 527, 559 and $636 \mathrm{~nm}$ those are observed at 20

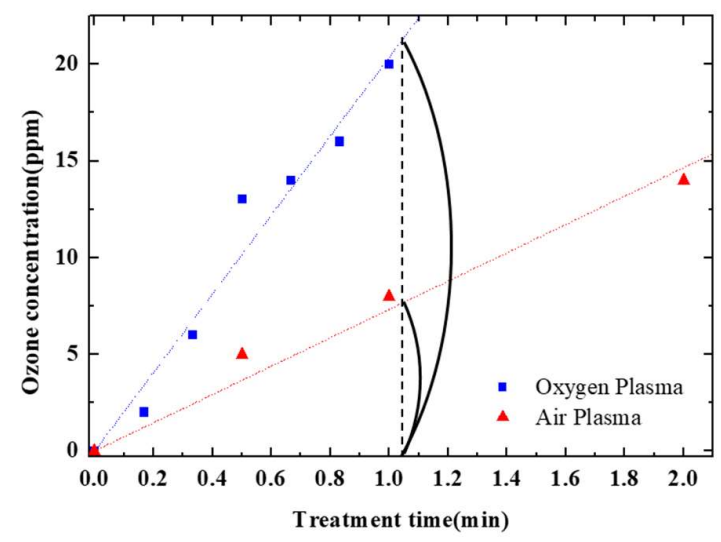

Figure 5 Ozone concentration in atmospheric plasmas changing ozone treatment time .

$\mathrm{Pa}$ are attributed to atomic oxygen $\mathrm{O}\left({ }^{3} \mathrm{P}\right), \mathrm{O}\left({ }^{1} \mathrm{~S}\right)$ and $\mathrm{O}\left({ }^{1} \mathrm{D}\right)$, respectively. These peaks cannot be observed at $80 \mathrm{~Pa}$ where the electron temperature decreases. Figure 4 shows the pressure dependence of light emission intensity from atomic oxygen $\mathrm{O}\left({ }^{5} \mathrm{P}\right)$ and singlet oxygen atom $\mathrm{O}\left({ }^{1} \mathrm{D}\right)$. The light emission intensity of $\mathrm{O}\left({ }^{5} \mathrm{P}\right)$ decreases with oxygen gas pressure, which is due to decrease of mean electron energy from the discharge by increase of electron - neutral collisions. The excitation energy of $\mathrm{O}\left({ }^{5} \mathrm{P}\right)$ is $5.1 \mathrm{eV}$. The number of energetic electrons decreases with the pressure, and then amount of atomic oxygen monotonically decreases. Pressure dependences of $\mathrm{OH}$ radical, $\mathrm{O}\left({ }^{3} \mathrm{P}\right), \mathrm{O}\left({ }^{1} \mathrm{~S}\right)$ and $\mathrm{O}\left({ }^{1} \mathrm{D}\right)$ are almost similar with $\mathrm{O}\left({ }^{5} \mathrm{P}\right)$. On the other hand, light emission intensity of singlet oxygen molecule $\mathrm{O}_{2}\left({ }^{1} \sum_{\mathrm{g}^{+}} \rightarrow{ }^{3} \sum_{\mathrm{g}^{-}}\right)$increases with pressure until $60 \mathrm{~Pa}$, and then decreases above $60 \mathrm{~Pa}$. The excitation energy of $\mathrm{O}_{2}\left({ }^{1} \Sigma_{\mathrm{g}^{+}}\right)$is relatively lower, $1.63 \mathrm{eV}$. When the pressure is in the range of 10 to $60 \mathrm{~Pa}$, production of atomic oxygens decreases and production of $\mathrm{O}_{2}\left({ }^{1} \Sigma_{\mathrm{g}^{+}}\right)$increases. Above $60 \mathrm{~Pa}$, electrons lose energy due to an increase in collisions, and the proportion of electrons that do not exceed the oxygen excitation energy increases, and then the production of $\mathrm{O}_{2}\left({ }^{1} \sum_{\mathrm{g}^{+}}\right)$decreased.

Atmospheric pressure plasma was generated from air or oxygen gas using dielectric barrier discharge, and was introduced into the stainless-steel chamber to control precisely the ozone CT value. Active oxygen species generated by the oxygen discharge produces the ozone in afterglow region of the atmospheric discharge. The ozone with long lifetime is transported to seed or leaf. The ozone reached the seed or leaf decomposes immediately to oxygen molecule of triplet state and singlet atomic oxygen $\mathrm{O}\left({ }^{1} \mathrm{D}\right)$ according to the reaction equation (1) $[29,30]$, by the catalytic action of metals in coenzyme of leaf cells:

$$
\mathrm{O}_{3} \rightarrow \mathrm{O}_{2}+\mathrm{O}\left({ }^{1} \mathrm{D}\right)
$$

Since atomic oxygens are difficult to be measured in general, the concentration or CT value of ozone is used as the index of atomic oxygen $\mathrm{O}\left({ }^{1} \mathrm{D}\right)$. The concentration and irradiation time of ozone are adjusted so that CT value is $1.0 \mathrm{ppm} \bullet \mathrm{min}$. Short lifetime active oxygen particles such as $\mathrm{OH}$ radical and atomic oxygen $\mathrm{O}\left({ }^{5} \mathrm{P}\right)$ are also generated in the plasma. The $\mathrm{OH}^{*}$ and $\mathrm{O}\left({ }^{5} \mathrm{P}\right)$ have short lifetime, and deactivate before arriving at plants. Figure 5 shows the change in ozone concentration in the chamber over plasma generation 
time. The ozone concentrations increase linearly with time. The oxygen gas discharge showed a high ozone concentration of about 2.8 times that of the air plasma.

Above results suggest that the major factor for the growth enhancement in both cases of irradiating seeds with low-pressure plasma and irradiating leaves with atmosphericpressure plasma is singlet oxygen atom $\mathrm{O}\left({ }^{1} \mathrm{D}\right)$. In each case of the low pressure and atmospheric pressure plasmas, amount of the active oxygen that irradiates seed and leaf is adjusted to the same using the CI due to controlling the concentration and irradiation time

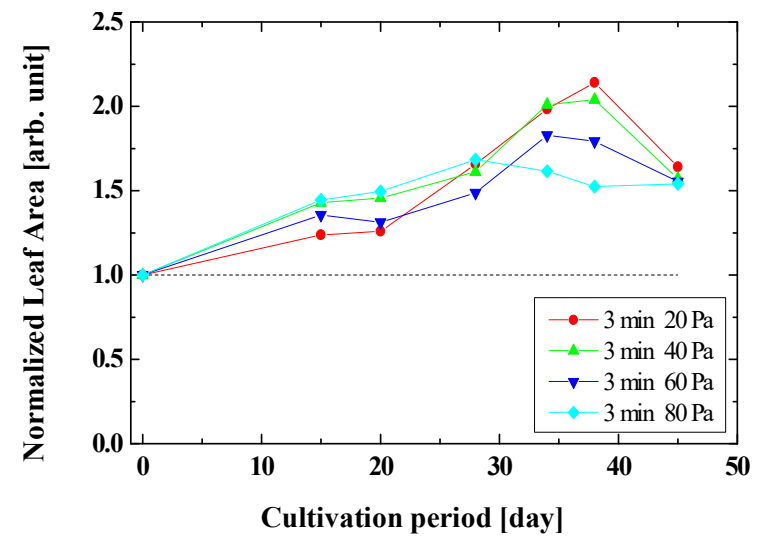

Figure 6 Cultivation period dependency of normalized leaf area by irradiation seeds with oxygen plasma for 3 min at different pressure.

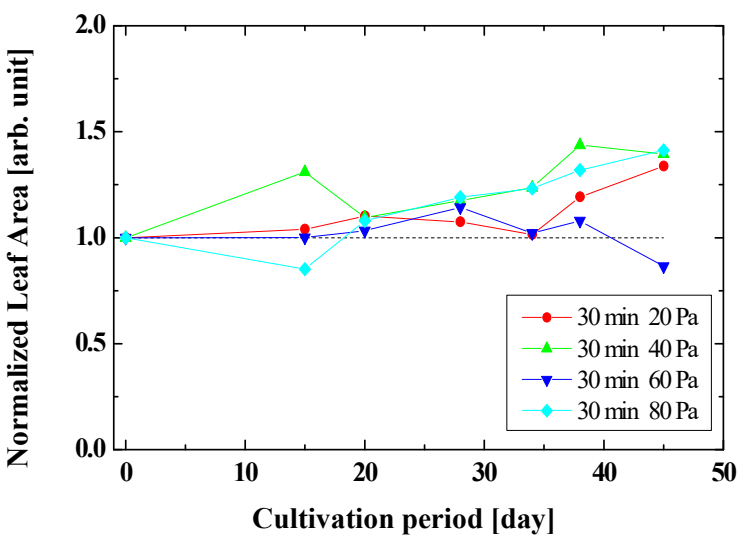

Figure 7 Cultivation period dependency of normalized leaf area by irradiation seeds with oxygen plasma for 30 min at different pressure.

of the active oxygen.

\subsection{Growth enhancement characteristics of leaf by irradiating seed with oxygen plasma}

Seeds of Arabidopsis thaliana irradiated with the low-pressure oxygen plasma for 3 minutes were seeded and cultivated. Figure 6 shows the leaf area of the Arabidopsis when the cultivation time is changed. The leaf area was normalized by that of unirradiated one. The leaf area became about 2.1 times after 40 days from the germination by irradiating oxygen plasma for 3 minutes with the oxygen pressure of $20 \mathrm{~Pa}$ as compared with that without plasma irradiation. Since the growth enhancement effect of leaves at the oxygen gas pressure of $80 \mathrm{~Pa}$ is almost same as that of $20 \mathrm{~Pa}, \mathrm{O}\left({ }^{5} \mathrm{P}\right)$ produced at any pressure would be the growth enhancement factor, and $\mathrm{O}\left({ }^{3} \mathrm{P}\right)$ has small effect on the leaf growth enhancement. Figure 7 shows the leaf area grown from the Arabidopsis seeds those are irradiated with the oxygen plasma for $30 \mathrm{~min}$. The leaf area becomes approximately 1.3 times after plasma irradiation for $30 \mathrm{~min}$ with the pressure of $60 \mathrm{~Pa}$. The leaf area tends to be larger with 3 min irradiation than with 30 min irradiation. Also, there is small effect of growth enhancement at around $60 \mathrm{~Pa}$. As shown in Fig. 4, light emission intensity of singlet oxygen molecule, $\mathrm{O}_{2}\left({ }^{1} \mathrm{~g}_{\mathrm{g}}{ }^{+}\right)$ is significant at $60 \mathrm{~Pa}$. Therefore, the $\mathrm{O}_{2}\left({ }^{1} \Sigma_{\mathrm{g}^{+}}\right)$did not induce a growth enhancement effect on plants, or leaf growth was suppressed by long-term plasma irradiation for about 30 minutes. From above results, regarding the

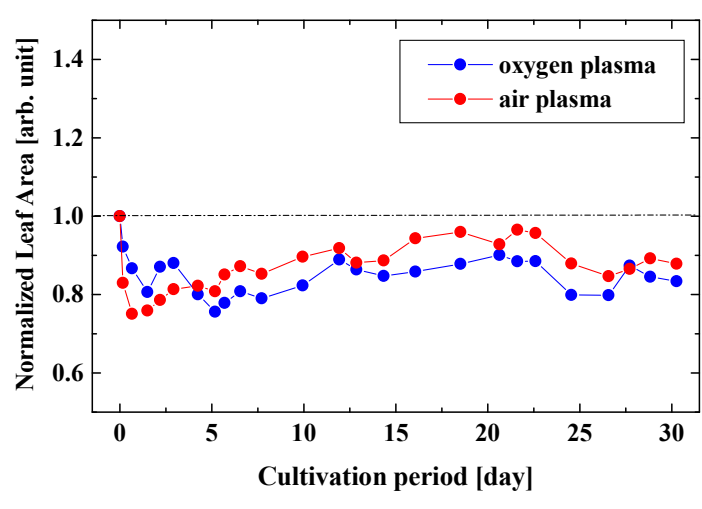

Figure 8 Cultivation period dependency of normalized leaf area irradiated with different irradiation conditions. 
growth of Arabidopsis leaves by irradiating seeds with the low-pressure oxygen plasma, irradiation of seeds with atomic oxygen would enhance the plant growth, and irradiation with excited oxygen molecules tends to suppress the leaf growth.

\subsection{Growth enhancement characteristics of leaf by irradiating seed with oxygen plasma}

Table 1 Typical annotations of expression-variable genes after irradiating seeds with oxygen plasma.

\begin{tabular}{|l|l|}
\hline $\begin{array}{l}\text { Functions and enzymes with increased } \\
\text { gene expression }\end{array}$ & $\begin{array}{l}\text { Functions and enzymes with reduced } \\
\text { gene expression }\end{array}$ \\
\hline \hline Photosynthetic electron transport chain & Methylation \\
\hline Redox reaction & DNA replication \\
\hline Response to Abscisic acid & Histone \\
\hline
\end{tabular}

Table 2 Annotation table of increased gene expression concerning antioxidative ability by irradiating seeds with oxygen plasma.

\begin{tabular}{|c|c|c|c|c|c|}
\hline Enrichment Score: 3.07 & (c) & 4 & Count & P_Value & Benjamini \\
\hline$\underline{\text { Oxidoreductase }}$ & $\underline{\mathrm{RT}}$ & $\equiv$ & 37 & $3.3 \mathrm{E}-5$ & $6.9 E-4$ \\
\hline oxidation-reduction process & $\underline{\mathrm{RT}}$ & 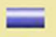 & 39 & $6.2 \mathrm{E}-4$ & $1.8 \mathrm{E}-2$ \\
\hline Iron & $\underline{\mathrm{RT}}$ & $\bar{\Xi}$ & 19 & $3.0 \mathrm{E}-2$ & $2.1 \mathrm{E}-1$ \\
\hline Enrichment Score: 2.01 & (G) & 4 & Count & P_Value & Benjamini \\
\hline $\begin{array}{l}\text { Superoxide dismutase, copper/zinc } \\
\text { binding domain }\end{array}$ & $\underline{\text { RT }}$ & $\overline{-}$ & 3 & $1.4 \mathrm{E}-3$ & $5.7 E-2$ \\
\hline $\begin{array}{l}\text { Superoxide dismutase }(\mathrm{Cu} / \mathrm{Zn}) / L \\
\text { chaperones }\end{array}$ & $\underline{\mathbf{R T}}$ & $\bar{\Xi}$ & 3 & $1.4 \mathrm{E}-3$ & $5.7 E-2$ \\
\hline removal of superoxide radicals & $\underline{\mathrm{RT}}$ & $\bar{a}$ & 3 & $1.6 \mathrm{E}-2$ & $2.5 \mathrm{E}-1$ \\
\hline Copper & $\underline{\mathrm{RT}}$ & $\bar{a}$ & 3 & $3.0 \mathrm{E}-1$ & $1.0 \mathrm{EO}$ \\
\hline
\end{tabular}

Table 3 Annotation table of increased gene expression concerning photosynthesis by irradiating seeds with oxygen plasma.

\begin{tabular}{|c|c|c|c|c|c|}
\hline Enrichment Score: 9.03 & (6) & 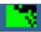 & Count & P_Value & Benjamini \\
\hline pigment binding & $\underline{\text { RI }}$ & $\bar{\Xi}$ & 13 & $3.8 \mathrm{E}-17$ & $1.1 \mathrm{E}-14$ \\
\hline $\begin{array}{l}\text { photosynthesis, light harvesting in } \\
\text { photosystem I }\end{array}$ & $\underline{\text { RT }}$ & $\bar{\Xi}$ & 13 & 1.7E-16 & $7.4 \mathrm{E}-14$ \\
\hline Photosvnthesis - antenna proteins & $\underline{\mathbf{R T}}$ & $\bar{\Xi}$ & 13 & $3.8 \mathrm{E}-16$ & $2.4 \mathrm{E}-14$ \\
\hline Chlorophyll $\mathrm{a} / \mathrm{b}$ binding_protein domain & $\underline{\mathbf{R T}}$ & $\bar{\Xi}$ & 13 & $5.6 \mathrm{E}-16$ & $2.5 \mathrm{E}-13$ \\
\hline Chlorophyll A-B binding_protein,_plant & $\underline{\mathbf{R T}}$ & 三 & 12 & $1.3 \mathrm{E}-15$ & $2.7 E-13$ \\
\hline Chlorophyll A-B binding_protein & $\underline{\mathbf{R T}}$ & $\bar{\Xi}$ & 13 & $1.8 \mathrm{E}-15$ & $2.7 \mathrm{E}-13$ \\
\hline Chlorophyll & $\underline{\mathbf{R T}}$ & $\bar{\Xi}$ & 13 & $7.5 E-15$ & $1.5 \mathrm{E}-12$ \\
\hline photosystem I & $\underline{\text { RT }}$ & 三 & 13 & $2.8 \mathrm{E}-14$ & $2.3 \mathrm{E}-12$ \\
\hline light-harvesting complex & $\underline{\mathbf{R T}}$ & 巨 & 11 & $5.6 \mathrm{E}-14$ & $2.3 \mathrm{E}-12$ \\
\hline Chromophore & $\underline{\text { RT }}$ & 三 & 14 & $8.7 E-14$ & $8.9 E-12$ \\
\hline chlorophyll binding & $\underline{\text { RT }}$ & 三 & 13 & $1.9 \mathrm{E}-13$ & $2.8 \mathrm{E}-11$ \\
\hline protein-chromophore linkage & $\underline{\mathrm{RT}}$ & 三 & 14 & $2.2 \mathrm{E}-13$ & 4.8E-11 \\
\hline Photosystem I & $\underline{\mathrm{RT}}$ & $\bar{\Xi}$ & 13 & 3.7E-13 & $2.6 \mathrm{E}-11$ \\
\hline Photosynthesis & $\underline{\text { RT }}$ & $\bar{\Xi}$ & 18 & $6.4 \mathrm{E}-13$ & $3.3 \mathrm{E}-11$ \\
\hline plastoglobule & $\underline{\mathrm{RT}}$ & $\bar{\Xi}$ & 15 & $3.4 \mathrm{E}-12$ & $9.0 \mathrm{E}-11$ \\
\hline photosystem II & $\underline{\text { RT }}$ & $\bar{\Xi}$ & 12 & $7.8 \mathrm{E}-12$ & $1.6 \mathrm{E}-10$ \\
\hline Photosystem II & $\underline{\text { RT }}$ & $\bar{\Xi}$ & 13 & $1.4 \mathrm{E}-11$ & $5.6 \mathrm{E}-10$ \\
\hline photosynthesis & $\underline{\mathrm{RT}}$ & $\bar{\Xi}$ & 17 & $1.1 \mathrm{E}-9$ & $1.5 E-7$ \\
\hline Thylakoid & $\underline{\mathrm{RT}}$ & $\equiv$ & 20 & $2.6 \mathrm{E}-8$ & $8.8 E-7$ \\
\hline thylakoid & $\underline{\mathbf{R T}}$ & $\bar{\Xi}$ & 17 & $5.9 E-8$ & $9.4 \mathrm{E}-7$ \\
\hline chloroplast thylakoid & $\underline{\text { RT }}$ & 三 & 16 & $3.5 E-7$ & $4.7 E-6$ \\
\hline chloroplast thylakoid membrane & $\underline{\text { RT }}$ & $\equiv$ & 21 & $2.3 \mathrm{E}-6$ & $2.6 \mathrm{E}-5$ \\
\hline
\end{tabular}

Arabidopsis leaf is irradiated with the oxygen plasma to investigate the growth enhancement of leaves. Area of leaves those are irradiated with atmospheric pressure plasma is shown in Fig. 8. Under all irradiation conditions, the area reduced to about $80 \%$ of that without the plasma irradiation on the 6th day after irradiation, and therefore the growth was suppressed by the plasma irradiation. This result is known as ozone damage in plants [31,32], and may cause problems especially in the plasma sterilization of agricultural products. Therefore, clarifying the details of ozone damage is indispensable for the progress of plasma sterilization technology. 


\subsection{Gene expression analysis of leaves by irradiating seeds with oxygen plasma}

To investigate biological reactions in plant after irradiating seeds with oxygen plasma, microarray analysis of RNA in leaf is performed. The RNA is extracted from the leaves cultivated for 4 weeks after sowing seeds those are irradiated with the low-pressure oxygen plasma, and then the gene expression variation from the control (un irradiated) are obtained. The irradiation conditions were an irradiation time of

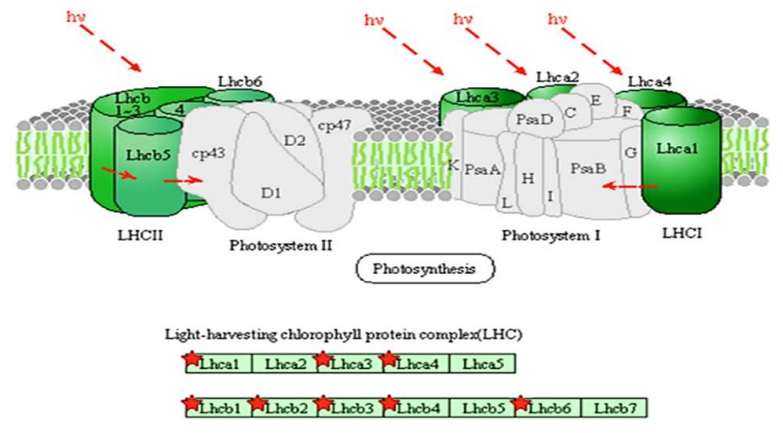

Figure 9 Signal pathway for the light-collecting chlorophyll protein complex, indicating activated reactions by oxygen plasma.

3 minutes and 30 minutes with

a gas pressure of $20 \mathrm{~Pa}$ where the atomic oxygen is dominant. There was no significant difference in the tendency of the gene expression variation when the irradiation time is changed, even though there is a remarkable difference in the growth enhancement effect with the irradiation time. This fact supports that the variation of gene expression is mainly caused by plasma irradiation on seeds.

The gene expression level of the leaves irradiated with plasma for 3 minutes was compared with that of the leaves without plasma irradiation, and the expression-variable genes were extracted. Table 1 shows the gene annotations those have changed statistically significantly among expression-variable genes. The gene expression levels of (1) antioxidant activity, (2) photosynthetic electron transport chain, (3) suppression of DNA methylation, (4) molecular chaperone activation were significant for the irradiation for 30 minutes. On the other hand, expression of genes related to (5) DNA replication was reduced. The following describes the detailed function of the gene whose expression variation was significantly increased by irradiation for 3 minutes or 30 minutes:

(1) Improvement of antioxidative activity: Increased expression of the gene group was observed. By irradiating oxygen plasma for 3 minutes, as shown in Table 2, it is involved in enzymes with antioxidant activity such as oxidoreductase and superoxide dismutase (SOD). CuZn-SOD acts as a catalyst for the removal of active oxygen in plant leaf greens [33]. It is inferred that the increase of these enzymes due to the variation in gene expression enhances the sugar production by photosynthesis and the promotion of growth by removing active oxygen in cells and blocking the inhibition of dark reaction. From the above, it was found that the improvement of antioxidant activity occurs over a long period of time by changing the gene expression by short-time oxygen plasma irradiation.

(2) Enhancement of photosynthesis: From the expression analysis results, it was found that the expression of genes related to the photosynthetic electron transport chain, including chlorophyll was significantly increased by irradiation for 3 minutes, as shown in Table 3 . The photosynthetic reaction obtains energy from light and produces organic molecules such as ATP from carbon dioxide and water in the atmosphere. Some enzymes involved in the Calvin cycle have one or more sets of -SH groups (thiol groups) that respond to redox, and when these are oxidized, they become -S-S- bonds (disulfide bonds). Enzymes with disulfide bonds are known to have reduced activity. Antioxidants induced by shortlifetime active oxygen irradiation may reduce the enzymes involved in the Calvin cycle and enhance the carbon fixation reaction. Figure 9 shows the pathway for the light-collecting chlorophyll protein complex of green plants whose gene expression was significantly increased by irradiation seeds with active oxygen species in the oxygen plasma for 3 minutes. It is considered that the plasma irradiation for a relatively short time, 3 minutes enhanced the function of photosynthesis by increasing the expression of some genes, and promoted the production of energy such as sugar and ATP essential for protein synthesis 


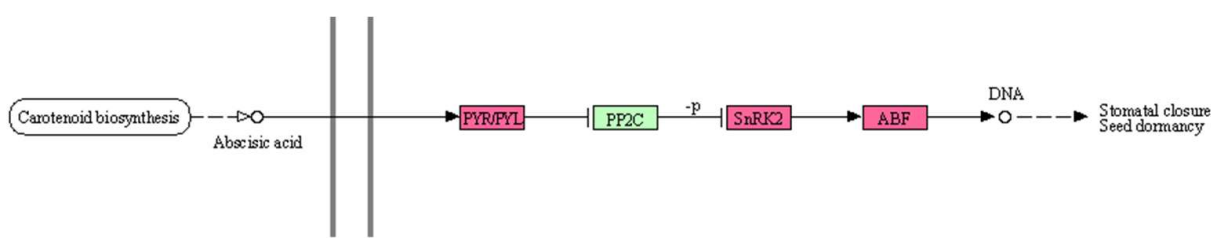

Figure 10 Signal pathway for response to abscisic acid synthesis, indicating activated reactions by oxygen plasma.

and then plant growth. On the other hand, when the seeds were irradiated with oxygen plasma for a long time, 30 minutes, there was no significant difference in the function of expressed genes, which was significantly different from that of the leaves irradiated for 3 minutes. There are two possibilities for the lack of growth-enhancement effect after 30minute irradiation: (i) direct non-gene-mediated damage by active oxygen species to the seeds, or (ii) the Calvin cycle catalytic enzyme is inactivated by being oxidized by plasma irradiation, the Calvin cycle is suppressed and the growth of leaves is suppressed.

(3) Suppression of DNA methylation: Gene concerning DNA methylation and epigenetics are found to be expressed by irradiation with the oxygen plasma [7-9]. The plasma irradiation for 3 minutes reduced the expression level of genes related to DNA methylation. Transcription and translation of the methylated portion of DNA is suppressed. Details of the observed epigenetic gene expression induced by the plasma irradiation is described in the previous papers [7-9].

(4) Activation of molecular chaperone: Hsp90 had a high gene expression level after 30 minutes of irradiation. Hsp90 is a molecular chaperone that interacts with various proteins, has a function of preventing protein aggregation during stress, and at the same time plays an important role in signal transduction [34,35]. The increased expression of HSP suggests that plasma irradiation caused abnormalities in the protein biosynthesis system, and that the growth-enhancement effect was suppressed compared to 3-minute irradiation.

(5) Decrease of DNA replication: The rate of cell division in the leaves decreases. On the other hand, since the leaf area was expanded, it is considered that this area expansion is not due to the increase in the rate of cell division but to the cell elongation. However, no increase in gene expression related to cell elongation could be confirmed. From these facts, it is possible that the expansion of the leaf area is due to the increase in turgor pressure of the cells due to the storage of water. If the photosynthetic function is improved, it may require a large amount of $\mathrm{H}_{2} \mathrm{O}$. In addition, the pores used for gas exchange with the atmosphere, which are essential for photosynthesis, close to suppress transpiration when the turgor pressure is low. Thus, storing water and keeping the turgor pressure high is necessary for efficient photosynthesis. In addition, as shown in Figure 10, the gene expression level of the response to abscisic acid (ABA), which is one of the plant hormones, was increased. Expression of the response to $\mathrm{ABA}$ increases in response to drought stress, and $\mathrm{ABA}$ contributes to the efficient use of water by closing the pores and suppressing the evaporation of water [36]. It is speculated that the response to abscisic acid increased the area by storing the water.

In the previous study, the seeds were irradiated with oxygen plasma and the gene expression of the seeds was analyzed. It was confirmed that genes that upwardly control each function of growth, stress response, hormone response, and photosynthesis were expressed. This leads to the enhancement of the energy production pathway $[6,8]$. Similarly, in the results of gene expression analysis of leaves in this experiment, an increase in gene expression related to stress responses such as photosynthetic function and antioxidant activity was confirmed. In addition, changes in gene expression related to epigenetics such as DNA methylation were confirmed in the same way as seeds. From this result, it was suggested that oxygen plasma irradiation of seeds affected gene expression even in the grown leaves and brought about a growth enhancement effect. 
From the above results, the pathway by which plasma irradiation causes leaf growth enhancement can be inferred as follows. In the case of irradiation for 3 minutes, the gene expression of seeds subjected to oxidative stress due to active oxygen in plasma changed to improve antioxidant activity and to suppress DNA methylation in leaves. Signals related to antioxidant activity are retained even after differentiation from seed to leaf. It is considered that the enzyme that catalyzes photosynthesis is reduced and activated by the improvement of the antioxidant activity. Also, the production of NADPH, which is a reducing agent, is increased and then the photosynthetic electron transfer reaction function would be enhanced. And genes concerning water storage to improve photosynthetic efficiency. From the above, it is inferred that the efficiency of photosynthesis and the increase in ATP synthesis led to the enhancement of leaf growth. One of reaction sequences from plasma irradiation seed to leaf growth enhancement is as follows:

1. Plasma irradiation of seeds

2. Seeds are subjected to oxidative stress and improve antioxidant activity

3. Obtained functions remains after germination (methylation: epigenetics)

4. Improvement of leaf antioxidant activity

5. Increase chlorophyll and activate photosynthetic electron transfer reaction

6. Increase water storage to improve photosynthetic efficiency, adjust circadian rhythm

7. Increase ATP synthesis

8. Promote growth (increase in leaf area).

According to the gene expression variation results, the plasma irradiation for 30 minute is expected to have the same growth enhancement effect as the 3-minute irradiation, on the other hand, the Calvin cycle is suppressed by long-term irradiation and the protein denaturation tends to occur. Therefore, the growth promoting effect would not be obtained.

\subsection{Gene expression analysis of leaves irradiated with atmospheric pressure plasma}

Genes whose expression varied were extracted in comparison with Arabidopsis thaliana unirradiated with plasma. Among these expression-variable genes, the gene annotations judged to be statistically significantly changed $(p<0.05)$ are shown in Table 4 of the annotation clustering. Increased expression of some genes involved in protein synthesis reactions was observed in the table. There was a marked increase in the expression of genes related to chaperone proteins and antioxidants. Chaperones act as catalysts in protein folding and perform endoplasmic reticulum-related degradation that removes abnormal proteins from the endoplasmic reticulum. Normally, chaperones remove abnormal proteins immediately, but when protein synthesis in the endoplasmic reticulum is active, the removal may not catch up and abnormal proteins may accumulate. At that time, a reaction called the endoplasmic reticulum stress response [37] that increases the production of factors such as chaperones occur.

Plasma irradiation of seeds increased the expression of some genes related to heat shock protein, which is a type of chaperone. Gene expression of heat shock proteins such as Hsp70 and Hsp90 was increased after the plasma irradiation, as shown in Table 5.

Table 4 Typical annotations of expression-variable genes after irradiating leaves with oxygen plasma.

\begin{tabular}{|l|l|}
\hline $\begin{array}{l}\text { Functions and enzymes with increased } \\
\text { gene expression }\end{array}$ & $\begin{array}{l}\text { Functions and enzymes with reduced } \\
\text { gene expression }\end{array}$ \\
\hline \hline Heat shock protein & Photosynthesis \\
\hline Redox reaction & glycoprotein \\
\hline & Methylation
\end{tabular}


Table 5 Annotation table of increased gene expression concerning heat shock proteins after irradiating leaves with oxygen plasma.

\begin{tabular}{|c|c|c|c|c|c|}
\hline Enrichment Score: $\mathbf{2 . 7 6}$ & (6) & 7 & Count & P_Value & Benjamini \\
\hline Heat shock protein 70 , conserved site & $\underline{\text { RI }}$ & $\bar{\Xi}$ & 7 & $5.6 \mathrm{E}-8$ & $2.8 \mathrm{E}-5$ \\
\hline Heat shock protein 70 family. & $\underline{\text { RT }}$ & $\bar{\Xi}$ & 7 & $2.9 \mathrm{E}-7$ & 4.8E-5 \\
\hline response to virus & $\underline{\mathbf{R T}}$ & $\overline{\mathrm{u}}$ & 4 & $2.3 \mathrm{E}-2$ & $3.4 \mathrm{E}-1$ \\
\hline Enrichment Score: $\mathbf{2 . 5 4}$ & (c) & 4 & Count & P_Value & Benjamini \\
\hline Heat shock protein Hsp $90, \mathrm{~N}$-terminal & $\underline{\mathbf{R T}}$ & i. & 4 & $1.2 \mathrm{E}-4$ & $1.2 \mathrm{E}-2$ \\
\hline Heat shock protein Hsp90, conserved site & $\underline{\mathbf{R T}}$ & $\overline{-}$ & 4 & $1.2 \mathrm{E}-4$ & $1.2 \mathrm{E}-2$ \\
\hline Heat shock protein $\mathrm{Hsp} 90$ & $\underline{\mathrm{RT}}$ & $\overline{-}$ & 4 & $1.2 \mathrm{E}-4$ & $1.2 \mathrm{E}-2$ \\
\hline heat shock protein, HSP90/HTPG types & $\underline{\mathrm{RT}}$ & - & 4 & $1.4 \mathrm{E}-4$ & $2.1 \mathrm{E}-3$ \\
\hline Ribosomal protein $\mathbf{S 5}$ domain 2-type fold & $\underline{\mathbf{R T}}$ & $\overline{\mathrm{u}}$ & 5 & $2.3 \mathrm{E}-2$ & $4.9 \mathrm{E}-1$ \\
\hline $\begin{array}{l}\text { Histidine kinase-like ATPase, ATP-binding } \\
\text { domain }\end{array}$ & $\underline{\mathbf{R T}}$ & i & 4 & 2.5E-2 & $5.0 \mathrm{E}-1$ \\
\hline HATPase $c$ & $\underline{\mathrm{RT}}$ & $\overline{-}$ & 3 & $3.4 \mathrm{E}-2$ & $6.9 \mathrm{E}-1$ \\
\hline Plant-pathogen interaction & $\underline{\mathbf{R T}}$ & $\bar{\Xi}$ & 8 & $3.6 \mathrm{E}-2$ & $2.5 \mathrm{E}-1$ \\
\hline
\end{tabular}

Table 6 Annotation table of increased gene expression concerning redox reactions after irradiating leaves with oxygen plasma.

\begin{tabular}{|c|c|c|c|c|c|}
\hline Enrichment Score: 3.03 & & & Count & P_Value & Benjamini \\
\hline response to endoplasmic reticulum stress & $\underline{\mathbf{R T}}$ & $\bar{\Xi}$ & 7 & $3.9 \mathrm{E}-7$ & $8.7 E-5$ \\
\hline Redox-active center & $\underline{\mathbf{R T}}$ & $\bar{\Xi}$ & 12 & $3.1 \mathrm{E}-6$ & $1.6 \mathrm{E}-4$ \\
\hline Disulphide isomerase & $\underline{\mathbf{R T}}$ & $\bar{\Xi}$ & 4 & $7.0 \mathrm{E}-5$ & $8.5 E-3$ \\
\hline protein disulfide isomerase activity. & $\underline{\text { RT }}$ & $\overline{\mathrm{a}}$ & 5 & $8.4 E-4$ & $1.2 \mathrm{E}-1$ \\
\hline domain:Thioredoxin 1 & $\underline{\text { RT }}$ & $\bar{\Xi}$ & 3 & $8.5 \mathrm{E}-4$ & $4.3 E-2$ \\
\hline $\begin{array}{l}\text { site:Lowers pKa of C-terminal Cys of second } \\
\text { active site }\end{array}$ & $\underline{\text { RT }}$ & $\bar{\Xi}$ & 3 & $8.5 E-4$ & 4.3E-2 \\
\hline $\begin{array}{l}\text { site:Lowers pKa of C-terminal Cys of first } \\
\text { active site }\end{array}$ & $\underline{\mathbf{R T}}$ & $\bar{\Xi}$ & 3 & $8.5 \mathrm{E}-4$ & $4.3 \mathrm{E}-2$ \\
\hline domain:Thioredoxin 2 & $\underline{\mathbf{R T}}$ & $\overline{\mathbf{a}}$ & 3 & $8.5 E-4$ & $4.3 \mathrm{E}-2$ \\
\hline Protein disulphide isomerase & $\underline{\mathbf{R T}}$ & $\bar{\Xi}$ & 3 & $1.4 \mathrm{E}-3$ & $9.3 \mathrm{E}-2$ \\
\hline Thioredoxin, conserved site & $\underline{\mathbf{R T}}$ & $\equiv$ & 5 & $1.6 \mathrm{E}-3$ & $9.3 \mathrm{E}-2$ \\
\hline Thioredoxin domain & $\underline{\text { RT }}$ & छ & 7 & $2.1 \mathrm{E}-3$ & $1.1 \mathrm{E}-1$ \\
\hline cell redox homeostasis & $\underline{\mathbf{R T}}$ & $\bar{\Xi}$ & 9 & $2.7 \mathrm{E}-3$ & $1.0 \mathrm{E}-1$ \\
\hline Thioredoxin-like fold & $\underline{\mathbf{R T}}$ & 三 & 11 & $5.4 \mathrm{E}-3$ & $2.2 \mathrm{E}-1$ \\
\hline
\end{tabular}

Hsp70 covers a wide range of proteins such as folding and association of nascent proteins, inhibition and repair of aggregation of proteins partially decomposed by stress such as heat, transport of proteins to cell organs, regulation of cell division and transcription, and regulation of protein activity. Hsp90 is a molecular chaperone that plays a role in preventing protein aggregation during stress, as described above. From the whole pathway of protein synthesis in endoplasmic reticulum, the expression of genes involved in the mechanism for detecting abnormal proteins (Protein Recognition by luminal chaperon) and the mechanism for removing abnormal proteins (ERAD) significantly increased by the plasma irradiation. In leaf cells, while atmospheric pressure plasma irradiation produced a growth-promoting effect, the growth would be suppressed as a result of damage such as protein denaturation. It is presumed that protein synthesis in the endoplasmic reticulum became active due to the recovery of the damaged site and the increase in resistance, and the molecular chaperone production improved in response to the accompanying accumulation of abnormal proteins those are generated by the plasma irradiation.

Table 6 shows a cluster of gene expression related to the redox reaction in which the expression variation was increased by the plasma irradiation leaves. Thioredoxin is a protein that functions as antioxidant that reduces disulfide bonds and promotes conversion to thiol groups [38,39]. As mentioned above, some enzymes involved in the carbon fixation reaction of photosynthesis, such as RubisCO, are activated by being reduced by antioxidative substances like Thioredoxin. Protein disulphide isomerase (PDI) is a protein with a Thioredoxin-like structure that catalyzes the thiol-disulfide exchange reaction of proteins and assists in the folding of proteins [40,41]. From the increase in the expression of these genes, it is inferred that proteins concerning the redox reactions in plants were 
Table 7 Annotation table of reduced gene expression concerning photosynthesis after irradiating leaves with oxygen plasma.

\begin{tabular}{|c|c|c|c|c|c|}
\hline Enrichment Score: 9.03 & os & 7 & Count & P_Value & Benjamini \\
\hline pigment binding & $\underline{\text { RT }}$ & $\bar{\Xi}$ & 13 & $3.8 \mathrm{E}-17$ & $1.1 \mathrm{E}-14$ \\
\hline $\begin{array}{l}\text { photosynthesis, light harvesting in } \\
\text { photosystem I }\end{array}$ & $\underline{\text { RT }}$ & $\bar{\Xi}$ & 13 & $1.7 \mathrm{E}-16$ & $7.4 \mathrm{E}-14$ \\
\hline Photosynthesis - antenna proteins & $\underline{\text { RT }}$ & 三 & 13 & $3.8 \mathrm{E}-16$ & $2.4 \mathrm{E}-14$ \\
\hline Chlorophyll $\mathrm{a} / \mathrm{b}$ binding_protein domain & $\underline{\mathrm{RT}}$ & 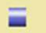 & 13 & $5.6 \mathrm{E}-16$ & $2.5 E-13$ \\
\hline Chlorophyll A-B binding_protein,_plant & $\underline{\text { RT }}$ & 三 & 12 & $1.3 E-15$ & $2.7 \mathrm{E}-13$ \\
\hline Chlorophyll A-B binding_protein & $\underline{\text { RT }}$ & $\bar{\Xi}$ & 13 & $1.8 \mathrm{E}-15$ & $2.7 \mathrm{E}-13$ \\
\hline Chlorophyll & $\underline{\text { RT }}$ & $\bar{\Xi}$ & 13 & 7.5E-15 & $1.5 \mathrm{E}-12$ \\
\hline photosystem I & $\underline{\text { RT }}$ & 三 & 13 & $2.8 \mathrm{E}-14$ & $2.3 \mathrm{E}-12$ \\
\hline light-harvesting complex & $\underline{\text { RT }}$ & $\bar{\Xi}$ & 11 & $5.6 \mathrm{E}-14$ & $2.3 \mathrm{E}-12$ \\
\hline Chromophore & $\underline{\mathrm{RT}}$ & $\bar{\Xi}$ & 14 & 8.7E-14 & $8.9 \mathrm{E}-12$ \\
\hline chlorophyll binding & $\underline{\mathrm{RT}}$ & $\overline{ }$ & 13 & $1.9 \mathrm{E}-13$ & $2.8 \mathrm{E}-11$ \\
\hline protein-chromophore linkage & $\underline{\text { RT }}$ & $\overline{ }$ & 14 & $2.2 \mathrm{E}-13$ & $4.8 \mathrm{E}-11$ \\
\hline Photosystem I & $\underline{\mathrm{RT}}$ & छ & 13 & $3.7 \mathrm{E}-13$ & $2.6 \mathrm{E}-11$ \\
\hline Photosynthesis & $\underline{\text { RT }}$ & $\bar{\Xi}$ & 18 & $6.4 \mathrm{E}-13$ & $3.3 \mathrm{E}-11$ \\
\hline plastoglobule & $\underline{\mathrm{RT}}$ & $\bar{\Xi}$ & 15 & $3.4 \mathrm{E}-12$ & $9.0 \mathrm{E}-11$ \\
\hline photosystem II & $\underline{\text { RT }}$ & $\bar{\Xi}$ & 12 & $7.8 \mathrm{E}-12$ & $1.6 \mathrm{E}-10$ \\
\hline Photosystem II & $\underline{\text { RT }}$ & 三 & 13 & $1.4 \mathrm{E}-11$ & $5.6 \mathrm{E}-10$ \\
\hline photosynthesis & $\underline{\text { RT }}$ & $\bar{\Xi}$ & 17 & $1.1 \mathrm{E}-9$ & $1.5 \mathrm{E}-7$ \\
\hline Thylakoid & $\underline{\text { RT }}$ & $\equiv$ & 20 & $2.6 \mathrm{E}-8$ & $8.8 \mathrm{E}-7$ \\
\hline thylakoid & $\underline{\text { RT }}$ & $\bar{\Xi}$ & 17 & $5.9 E-8$ & $9.4 \mathrm{E}-7$ \\
\hline chloroplast thylakoid & $\underline{\text { RT }}$ & $\bar{\Xi}$ & 16 & $3.5 \mathrm{E}-7$ & $4.7 E-6$ \\
\hline chloroplast thylakoid membrane & $\underline{\text { RT }}$ & $\equiv$ & 21 & $2.3 \mathrm{E}-6$ & $2.6 \mathrm{E}-5$ \\
\hline
\end{tabular}

Table 8 Annotation table of reduced gene expression concerning glycoproteins after irradiating leaves with oxygen plasma.

\begin{tabular}{|c|c|c|c|c|c|}
\hline Enrichment Score: $\mathbf{5 . 7 5}$ & (E) & & Count & P_Value & Benjamini \\
\hline Signal & $\underline{\text { RT }}$ & $\bar{\square}$ & 150 & $1.4 \mathrm{E}-11$ & $3.2 \mathrm{E}-9$ \\
\hline extracellular region & $\underline{\mathbf{R T}}$ & 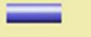 & 99 & $3.2 E-6$ & $2.0 \mathrm{E}-4$ \\
\hline Glycoprotein & $\underline{\text { RT }}$ & $\equiv$ & 71 & $7.7 E-6$ & $9.0 \mathrm{E}-4$ \\
\hline signal peptide & $\underline{\text { RT }}$ & $\bar{\equiv}$ & 67 & $1.0 \mathrm{E}-5$ & $5.4 E-3$ \\
\hline Secreted & $\underline{\text { RT }}$ & $\equiv$ & 54 & $4.2 \mathrm{E}-5$ & $3.3 \mathrm{E}-3$ \\
\hline glycosylation site: $\mathrm{N}$-linked (GlcNAc...) & $\underline{\text { RT }}$ & $\equiv$ & 46 & $2.1 E-4$ & $5.4 \mathrm{E}-2$ \\
\hline
\end{tabular}

oxidized by the plasma irradiation. It is inferred that the active species in the plasma have reached the inside of the plant.

Genes with reduced gene expression are investigated. Table 7 shows the cluster of gene expression related to photosynthesis in which gene expression was reduced. The gene expression concerning the photosynthetic electron transfer reaction function was significantly reduced in this experiment. The gene expression level of the light-harvesting chlorophyll protein complex (LHC) containing chlorophyll was decreased by plasma irradiation [42]. Table 8 shows the cluster of gene expression for glycoproteins whose gene expression was reduced. In many cases, oligosaccharides covalently bind to proteins that enter the endoplasmic reticulum cavity or endoplasmic reticulum membrane to become glycoproteins. It is suggested that the production amount of sugar produced decreased because the amount of ATP, which is the energy in the body, decreased due to the impaired photosynthetic function, and the production of glycoprotein was also suppressed accordingly. One of reaction sequences from plasma irradiation leaf to growth enhancement of leaf is as follows:

\section{Plasma irradiation of leaves}

2. Damage to the photosystem antenna complex due to oxidative stress

3. Decrease in reaction rate of photosynthetic electron transfer reaction

4. Increased production of chaperone for protein repair

5. Decrease of ATP and sugar synthesis amount due to carbon fixation reaction

6. Protein decrease in biosynthesis 
7. Promote growth (increase in leaf area)

Table 9 Typical annotations of expression-variable genes after irradiating leaves with air plasma.

\begin{tabular}{|l|l|}
\hline $\begin{array}{l}\text { Functions and enzymes with increased gene } \\
\text { expression }\end{array}$ & $\begin{array}{l}\text { Functions and enzymes with reduced gene } \\
\text { expression }\end{array}$ \\
\hline \hline Biodefense reaction & Glycoprotein \\
\hline Redox reaction & Growth factor \\
\hline & Protein phosphorylation \\
\hline
\end{tabular}

To investigate the effect of nitrogen species on the gene expression variations of the plant, atmospheric air discharge plasma is employed to irradiate the plant leaves. Table 9 shows gene annotations those have statistically significantly changed between the expressed genes in Arabidopsis leaves those had been exposed to the atmospheric air plasma for 30 seconds and the genes of the unirradiated leaves. The ozone CT values of the atmospheric oxygen and air plasmas are same, $1.0 \mathrm{ppm} \bullet \mathrm{min}$, to reveal the effect of active nitrogen species in the air plasma. There was almost no significant difference between the air and the oxygen plasmas in the function of the expressed gene that was significantly varied compared to the atmospheric oxygen plasma case. Also, the main reaction pathways of the plant for the air and the oxygen plasmas are almost similar. Compared with oxygen plasma, nitrogen-based active species are produced in air plasma, but the influence of oxygen-active species is large on plants.

\subsection{Comparison of leaf gene expression variation analysis before and after germination}

The gene expression analysis of the leaves that were plasma-irradiated to the seeds before germination is compared with the leaves that were plasma-irradiated to seeds after germination. Gene expression related to photosynthetic function increased when plasma irradiation was performed before germination, but decreased when plasma irradiation was performed after germination. Gene expression related to stress response such as antioxidant activity tended to increase under both conditions. From these facts, it is speculated that it is possible to improve the resistance of leaves to oxidative stress after germination by irradiating them with plasma before germination. If it has resistance to oxidative stress due to plasma irradiation, it may be applicable to agricultural product sterilization with ozone.

\section{Conclusion}

Plasma irradiation was performed on Arabidopsis seeds and leaves to investigate the mechanism of plant growth enhancement and to clarify the effect of plasma irradiation during the growth process. Gene expression analysis was performed on the leaves grown from the seeds irradiated with plasma and the leaves irradiated with plasma after germination. The list of the obtained results is described below:

1. The leaf area of Arabidopsis promotes growth up to 2.1 times by irradiation of seeds with low-pressure oxygen plasma. On the other hand, plasma irradiation of the leaves suppressed the growth about 0.8 times.

2. Plasma irradiation of seeds significantly increased gene expression related to leaf photosynthesis, antioxidant activity and water storage. From this, it is presumed that the production of NADPH was increased by photosynthesis as the oxidation resistance to plasma irradiation, and the water storage was improved accordingly, leading to the promotion of growth.

3. Comparing the results of gene expression analysis of seeds and leaves after plasma irradiation of seeds, it was confirmed that both seeds and leaves had increased gene expression related to the same function such as photosynthesis. This suggests that plasma 
irradiation of seeds also affects leaf gene expression, and it is considered that this phenomenon is related to epigenetic changes such as methylation.

4. Plasma irradiation of leaves reduced gene expression related to leaf photosynthesis. On the other hand, the antioxidant activity of the leaves increased.

Acknowledgments: Authors express their gratitude to Prof. Takaki, Prof. Wang and Prof. Takahashi for fruitful discussion. This work was supported by JSPS KAKENHI Grant Numbers 19H05611, $20 \mathrm{H} 01892$.

\section{References}

1. A.E. Dubinov; E.R. Lazarenko; V.D. Selemir, Effect of glow discharge air plasma on grain crops seed, IEEE Trans. on Plasma Sci. 2000, 28, 180-183.

2. Nobuya Hayashi, Reoto Ono and Shohei Uchida, Growth Enhancement of Plant by Plasma and UV Light Irradiation to Seeds, J. Photopolym. Sci. Technol. 2015, 28, 445-448.

3. Reoto Ono and Nobuya Hayashi, Variation of antioxidative activity and growth enhancement of Brassicaceae induced by lowpressure oxygen plasma, Jpn. J. Appl. Phys. 2015, 54, 06GD03-1 - 06GD03-4.

4. Jiang Jiafeng, He Xin, Li Ling, Li Jiangang, Shao Hanliang, Xu Qilai, Ye Renhong and Dong Yuanhua, Effect of Cold Plasma Treatment on Seed Germination and Growth of Wheat, Plasma Sci. Technol. 2014, 16, 54-58.

5. Li Ling, Jiang Jiafeng, Li Jiangang, Shen Minchong, He Xin, Shao Hanliang \& Dong Yuanhua, Effects of cold plasma treatment on seed germination and seedling growth of soybean, Sci. Rep. 2014, 4, 5859.

6. Satoshi Watanabe, Reoto Ono, Nobuya Hayashi, Kousuke Tashiro, Satoru Kuhara, Asami Inoue, Kaori Yasuda, and Hiroko Hagiwara, Growth Enhancement and Gene Expression of Arabidopsis irradiated by active oxygen species, Jpn. J. Appl. Phys. 2016, 55, 07LG10-1 - 07LG10-6.

7. Riku Nakano, Kosuke Tashiro, Reona Aijima, and Nobuya Hayashi, Effect of oxygen plasma irradiation on gene expression in plant seeds induced by active oxygen species, Plasma Medicine 2016, 6, 303-313.

8. Nobuya Hayashi, Reoto Ono, Riku Nakano, Masaharu Shiratani, Kosuke Tashiro, Satoru Kuhara, Kaori Yasuda, and Hiroko Hagiwara, DNA microarray analysis of plant seeds irradiated by active oxygen species in oxygen plasma, Plasma Medicine 2016, $6,459-471$.

9. Riku Nakano, Yoshio Yamashita, Akira Kobayashi, Nobuya Hayashi, Gene expression effect of plant seeds by irradiation with low-pressure oxygen plasma, Journal of IAPS 2018, 26, 91-95.

10. Takaki, Koichi, Hayashi, Nobuya, Wang, Douyan, Ohshima Takayuki, High-voltage technologies for agriculture and food processing, J. Phys. D: Appl. Phys. 2019, 52, 473001 (42pp) .

11. Akiko Maruyama-Nakashita, Yohei Ishibashi, Kyotaro Yamamoto, Liu Zhang, Tomomi Morikawa-Ichinose, Sun-Ju Kim, Nobuya Hayashi, Oxygen plasma modulates glucosinolate levels without affecting lipid contents and composition in Brassica napus seeds, Bioscience, Biotechnology, and Biochemistry 2021, 85, 2434-2441.

12. Nobuya Hayashi and Yoshihito Yagyu, Treatment of protein using oxygen plasma produced by RF discharge, Trans. of the Material Research Society of Japan 2008, 33, 791-794.

13. Yoshihito Yagyu, Nobuya Hayashi, Weimin Guan, Hiroharu Kawasaki, Influence of Atomic and Singlet Molecular Oxygen Generated by RF Plasma on Reduction of Protein, J. Plasma and Fusion Research 2009, 8, 578-581.

14. Nobuya Hayashi, Akari Nakahigashi, Hao LIU, Masaaki Goto, Treatment of second order structures of protein using oxygen RF plasma, Jpn. J. Appl. Phys. 2010, 49, 08JH02-1 - 08JH02-4.

15. Nobuya Hayashi, Ryo Kometani, Yuki Yoshida, Treatment of dipicolinic acid and inactivation mechanism of thermophile spore using active oxygen, Jpn. J. Appl. Phys. 2013, 52, 11NF03-1 - 11 NF03-4.

16. R. Ono, A. Tanaka, S. Uchida, S. Kitazaki, T. Itarashiki and N. Hayashi, Effect of Active Oxygen Species in Low Pressure Oxygen Plasma on Antioxidative Substances, Frontier of Applied Plasma Technology 2014, 7, 45-46.

17. N. Hayashi, R. Ono, Y. Yagyu, A. Yonesu, Application of atmospheric discharge plasma to agricultural and marine products, $J$. Jpn. Soc. Appl. Electromagnetics and Mechanics 2014, 22, 447-452.

18. Nobuya Hayashi, Yukie Miyamaru, Reona Aijima, Yoshio Yamashita, Activation of p53-mediated apoptosis pathway in HSC3 cancer cell irradiated by atmospheric DBD oxygen plasma, IEEE Transactions on Plasma Science 2018, 47, 1093-1099.

19. Nobuya Hayashi, Yuki Inoue, Yukari Kyumoto, Toshio Kukita, Characteristics of differentiation of osteoclast cells irradiated with active species in atmospheric oxygen plasma, Jpn. J. Appl. Phys. 2020, 59, SJJF02.

20. Sitti Subaedah, Haruka Uematsu, Nobuya Hayashi, Activation of EL-4 T-cells by irradiation with atmospheric oxygen plasma, Jpn. J. Appl. Phys. 2020, 59, SJJF03.

21. G. Gordon, The chemistry and reactions of ozone in our environment, Progress in Nuclear Energy 1995, $29,89-96$.

22. Fumiaki Mitsugi, Tomoya Abiru, Tomoaki Ikegami, Kenji Ebihara, Shin-Ichi Aoqui, Kazuhiro Nagahama, Influence of Ozone Generated by Surface Barrier Discharge on Nematode and Plant Growth, IEEE Transactions on Plasma Science 2016, 44, 30713076 . 
23. Seisaku Ohshiro, Masata Katsuto, Kosei Satahira, Yu Iriyama, Keiko Nakamura, Seisiro Ito, Tatsuhiko Ihara, Fabrication of the Plasma-Chemical Indicator and It's Application, J. Photopolym. Sci 2013, 26, 533-538.

24. Kosei Satahira, Seisaku Ohshiro, Keiko Nakamura, Seisiro Ito, Tatsuhiko Ihara, Visualization Plasma Diagnosis Indicator Using Discoloration Reaction of Au and Pt Ions, J. Photopolym. Sci 2015, 28, es 435-438.

25. Dennis G Jr, Sherman BT, Hosack DA, Yang J, Gao W, Lane HC, Lempicki RA, DAVID: Database for Annotation, Visualization, and Integrated Discovery, Genome Biol 2003, 4, P3.

26. D. W. Huang, B. T. Sherman, Q. Tan, J. R. Collins, W. G. Alvord, J. Roayaei, R. Stephens, M. W. Baseler, H. C. Lane, and R. A. Lempicki, The DAVID Gene Functional Classification Tool: a novel biological module-centric algorithm to functionally analyze large gene lists, Genome Biol. 2007, 8, R183.

27. G. A. Germany, R. J. Anderson, and G. J. Salamo, Electron impact excitation of the 3p(5P) state of atomic oxygen, J. Chem. Phys., $1988,89,1999-2002$.

28. H. M. Katsch, A. Tewes, E. Quandt, A. Goehlich, T. Kawetzki, and H. F. Döbele, Detection of atomic oxygen: Improvement of actinometry and comparison with laser spectroscopy, J. Appl. Phys., 2000, 88, 6232-6238.

29. F. Kaufman, The air afterglow and its use in the study of some reactions of atomic oxygen, Proc. the Royal Society of London. Series A 1958, 247, 123-139.

30. J. Waskoenig, K. Niemi, N. Knake, L. M. Graham, S. Reuter, V. Schulz-von der Gathen and T. Gans, Atomic oxygen formation in a radio-frequency driven micro-atmospheric pressure plasma jet, Plasma Sources Sci. Technol. 2010, $19,045018$.

31. S Rich, Ozone damage to plants, Annu. Rev. Phytopathol. 1964, 2, 253-266.

32. P. R. Miller, J. R. Parmeter Jr., O. C. Taylor, E. A. Cardiff, Ozone injury to the foliage of Pinus ponderosa, Phytopathology, 1963, 53, 1072-1076.

33. Leonardo M. Casano, Leonardo D. Gómez, Hernán R. Lascano, Claudio A. González, Victorio S. Trippi, Inactivation and Degradation of CuZn-SOD by Active Oxygen Species in Wheat Chloroplasts Exposed to Photooxidative Stress, Plant and Cell Physiology 1997, 38, 433-440.

34. Klaus Richter, Johannes Buchne, Hsp90: Chaperoning signal transduction, Journal of cellular physiology 2001, 188, 281-290.

35. Mechanisms of Hsp90 regulation, Chrisostomos Prodromou, Biochem J. 2016, 473, 2439-2452.

36. Y. Zhao, J. Gao, J. I. Kim, K. Chen, R. A. Bressan and J.-K. Zhu, Control of Plant Water Use by ABA Induction of Senescence and Dormancy: An Overlooked Lesson from Evolution, Plant and Cell Physiology 201, 58, 1319-1327.

37. David Ron, Translational control in the endoplasmic reticulum stress response, J. Clin. Invest. 2002, 110, $1383-1388$.

38. E. Gelhaye, N. Rouhier, N. Navrot \& J. P. Jacquot, The plant thioredoxin system, Cell. Mol. Life Sci. 2005, 62, 24-35.

39. Jun Lu, Arne Holmgren, The thioredoxin antioxidant system, Free Radic. Biol. Med. 2014, 66, 75-87.

40. Jeffrey C. Edman, Leland Ellis, Russell W. Blacher, Richard A. Roth \& William J. Rutter, Sequence of protein disulphide isomerase and implications of its relationship to thioredoxin, Nature 1985, 317, 267-270.

41. Author links open overlay panelRobert B.FreedmanTim R.HirstMick F.Tuite, Protein disulphide isomerase: building bridges in protein folding, Trends Biochem. Sci. 1994, 19, 331-336.

42. Stefan Jansson, The light-harvesting chlorophyll ab-binding proteins, Biochim. Biophys. Acta 1994, 1184, 1-19. 